\title{
Discourse behavior of possessives reflects the importance of interpersonal relationships
}

\author{
Jesse Storbeck \& Elsi Kaiser*
}

\begin{abstract}
Nominal possessive constructions (e.g. Sam's car) present a challenge for theories of discourse since, unlike simpler nominal phrases (e.g. a car), they explicitly refer to two entities, not just one. Research on the discourse prominence of these two referents has been limited in scope and produced contradictory findings. We use a sentence continuation experiment to investigate the prominence of possessions as a function of their animacy. We find that possessed animates (e.g. her butler) are especially prominent. Their privileged status in discourse may relate to non-linguistic theories on the importance of interpersonal relationships.
\end{abstract}

Keywords. psycholinguistics; discourse; possessives; sentence continuation

1. Introduction. A widely held view about discourse-level representation and processing is that referents in a given discourse vary in prominence (alternatively, 'salience') and that the prominence of referents changes over time as the discourse unfolds (e.g. Ariel, 1988; van den Broek et al., 1996). Many factors contribute to a referent's prominence, but two of the most influential and dependable predictors are grammatical role and animacy; specifically, subjects tend to be more prominent than objects (e.g. Chafe, 1976; Crawley et al., 1990), and animates tend to be more prominent than inanimates (e.g. Bock et al., 1992; Dahl \& Fraurud, 1996). However, to the best of our knowledge, prior work has tended to overlook a frequent grammatical structure with potential to inform current theories of discourse: nominal possessive constructions (e.g. Sam's car, Sam's doctor). Unlike simpler nominals (a car, the doctor), nominal possessives reference two entities, a possessor (Sam) and a possession (car/doctor) within the same noun phrase.

Since most previous work investigating the discourse prominence of referents has focused on nominal phrases containing a single referent, the lack of research on possessives brings up two main questions. Firstly, how are the two entities represented in discourse? Do they simply behave like independent discourse referents, or are their representations linked somehow? The latter seems to be necessary if we hope to encode the possessive relationship in the discourse. Secondly, if the two discourse referents are linked, does the link differ across different types of semantic possession relations? This question is particularly notable for languages like English, which use the same syntactic configuration to express a variety of relations between the possessor and possession, such as ownership (e.g. Sam's book), part-whole (e.g. Sam's arm), and kinship (e.g. Sam's mother). In contrast, other languages, such as Maltese, use different morphosyntactic mechanisms to express different types of possession relations. For example, Maltese id 'hand' and ktieb 'book' require different morphosyntax to form possessives: $i d-i$ 'my hand' (part-whole relation) and il-ktieb tiegh-i 'my book' (ownership relation) (Haspelmath, 2017).

Before proceeding further, we should note that the type of nominal possessive exemplified by Sam's car is sometimes known as an 's-genitive'; however, English also realizes nominal possessives with the 'of-genitive' structure (e.g. the floor of the bedroom, the capital of Califor-

${ }^{*}$ The authors gratefully acknowledge the audience at the Experiments in Linguistic Meaning conference, virtually hosted by the University of Pennsylvania, for their useful comments and feedback. We also thank the members of the USC Language Processing Lab for their input. Additional thanks are due to Madeline Rouse for assisting with the data annotation. Authors: Jesse Storbeck, University of Southern California (jstorbec@usc.edu) \& Elsi Kaiser, University of Southern California (emkaiser@usc.edu). 
nia). This study focuses on English $s$-genitives for multiple reasons. Firstly, animate possessors exhibit a broad range of semantic possession types - key for investigating how different possession relations affect discourse-level representation-yet animates are typically dispreferred as possessors in of-genitives (e.g. Rosenbach 2002). Additionally, our work will involve pronouns, which can be ungrammatical or degraded as possessors in of-genitive constructions (e.g. the palace of the king vs. * the palace of him; the roof of the house vs. ?the roof of it) (e.g. Rosenbach 2002).

The present study investigates how nominal possessive constructions are encoded in discourse and how different semantic possession relations affect the discourse-level representations for the referents involved in possessives. We begin by reviewing prior work on the discourse properties of possessives, which comes from applications of Centering Theory (e.g. Grosz et al., 1995) (Section 1.1). We also summarize some relevant research on interpersonal relationships, which possessives explicitly denote when both the possessor and possession are human (Section 1.2). Based on existing work, we then propose three hypotheses about the discourse prominence of possessed referents (Section 1.3). In Section 2, we test our hypotheses using a sentence continuation task. In Section 3, we present our results, which suggest that possessed animate referents are especially prominent in discourse. We conclude (Section 4) in favor of theory that links the general cognitive importance of interpersonal relationships with the apparently privileged discourse representations of their linguistic realizations.

1.1. Previous approaches BASED ON CENTERING TheOry. While the discourse behavior of nominal possessives has generally received little attention in psycholinguistic literature, some researchers have approached this issue within the framework of Centering Theory (Grosz et al., 1995). Centering Theory is a model of discourse coherence which seeks to capture patterns in transitions from one utterance to another (e.g. what makes a particular sequence of utterances more or less coherent as a discourse). Centering Theory is particularly relevant to the present study because a key component of its algorithm is ranking referents according to their prominence. Given the frequency of nominal possessive constructions and the fact that most work within Centering Theory has been corpus-based, it is not surprising that this framework in particular has had to address nominal possessive constructions.

Within Centering Theory, researchers have argued for two competing accounts of the relative prominence of possessors and possessions. On the one hand, Chae (2003) follows the Complex NP Assumption of Walker \& Prince (1996), which posits that the discourse referents realized within a complex noun phrase - of which possessives are one type - are ranked from most to least prominent based on their left-to-right order. Therefore, possessors in $s$-genitives are more prominent than their possessions (e.g. in Sam's car, Sam would outrank car in prominence). On the other hand, Di Eugenio (1998) proposes (for possessives involving animate possessors) that the ranking depends on the animacy of the possession; animate possessions immediately outrank their possessors, while inanimate possessions are ranked immediately below their possessors. Accordingly, in Sam's car, Sam would still outrank car, but in Sam's doctor, doctor would outrank Sam. This theory dovetails with the well-documented cross-linguistic finding in the broader discourse literature that animate referents tend to be more prominent than inanimate ones (e.g. Bock et al., 1992; Dahl \& Fraurud, 1996; Dahl, 2008). For instance, animate referents tend to appear before inanimates and in subject position (e.g. Branigan et al., 2007; Prat-Sala \& Branigan, 2000). Additionally, animacy influences the linguistic form with which a referent is mentioned, with animates being overall more likely to be pronominalized than inanimates (Arnold \& Griffin, 2007; Fukumura \& van Gompel, 2011). 
Notwithstanding the debate within Centering Theory on how to deal with nominal possessives, both of these competing accounts leave an important question unanswered: how does being possessed affect a referent? For instance, if we compare possessive constructions like Sam's car to simpler noun phrases like the car or a car, will there be any difference in the discourse prominence of car? Given that a key goal of theories of discourse representation is to shed light on the factors that modulate a referent's prominence, an understanding of the effect of possession itself is needed in a theory of the discourse behavior of nominal possessives.

1.2. THE IMPORTANCE OF INTERPERSONAL RELATIONSHIPS. When the possessor and possession in a possessive construction are both animate and human, the construction explicitly denotes an interpersonal relationship. Such relationships may be permanent (e.g. Sam's mother, the teacher's son) or more transitory (e.g. their neighbor, the accountant's boss) and may vary with respect to the formality of the relationship's definition (e.g. strictly biological relations vs. gradient social relations). Nevertheless, in all possessives where both possessor and possession are human, the two individuals stand in some kind of socially salient and not-entirely transient relation to each other (i.e. an interpersonal relationship).

In non-linguistic research, interpersonal relationships have been shown to be critical for human health and well-being (e.g. Cacioppo \& Hawkley, 2009; Eisenberger \& Cole, 2012). For instance, social connectedness has been linked to longevity and disease resistance (e.g. Miller et al., 2009; Holt-Lunstad et al., 2010), while loneliness is correlated with depression and cognitive decline (e.g. Tilvis et al., 2004; Cacioppo et al., 2006). In short, this literature makes clear that people with stronger connections to others tend to live longer, happier lives, while socially isolated individuals tend to suffer a variety of negative consequences.

Furthermore, prior research on memory shows that people tend to form stronger memory representations for animate entities than for inanimates (e.g. Nairne et al., 2013; Bonin et al., 2014). This observation has led some researchers to theorize that that better memory for animates arose from the evolutionary importance of identifying threats, mates, and social groups, most of which entail interpersonal relationships (e.g. Nairne, 2010; VanArsdall et al. 2013).

Based on such findings, the human mind appears to be especially attuned to interpersonal relationships. Therefore, one might expect nominal possessives that express interpersonal relationships to also be privileged in our mental representations, relative to other kinds of possessive relations. The experiment reported in this paper explores whether these general cognitive tendencies have any effect on a referent's discourse prominence, as reflected by language production. Before turning to the experiment itself, we next outline three possible hypotheses about the discourse representations of possessed referents.

\subsection{THREE HYPOTHESES CONCERNING THE DISCOURSE REPRESENTATIONS OF POSSESSIONS. Based} on prior work, we propose and test three novel hypotheses about the discourse representations of possessed referents. Importantly, the first two hypotheses are not mutually exclusive; the third hypothesis supersedes the previous two, while not necessarily invalidating their underlying logic.

The first hypothesis is the Animacy Hypothesis. Animate referents are widely viewed as more prominent in discourse and memory, since they tend to be mentioned earlier (e.g. Bock et al., 1992; Dahl, 2008), are more frequently pronominalized (e.g. Arnold \& Griffin, 2007; Fukumura \& van Gompel, 2011), and persist in memory (in both a linguistic and domain-general sense) more than inanimates (e.g. Nairne et al., 2013; Bonin et al., 2014). Therefore, the Animacy Hypothesis proposes that animate possessions (e.g. Sam's doctor) are more prominent in discourse than inanimate ones (e.g. Sam's $\underline{\text { car }}$ ) for the same reasons and to the same extent that simpler nominals exhibit animacy effects (the/a doctor vs. the/a car).

Jesse Storbeck and Elsi Kaiser:

Discourse behavior of possessives reflects the importance of interpersonal relationships. 
The second hypothesis is the Possessive Hypothesis. Nominal possessives like Sam's car are referentially and semantically more complex than simpler nominals due the presence of an additional referent and the link between possessor and possession. Since increased representational complexity has been shown to promote retrieval from memory (e.g. Fisher \& Craik, 1980; Hofmeister, 2011; Karimi \& Ferreira, 2016; Troyer et al., 2016), we might expect possessions to be more prominent than simpler nominals on the discourse level. Therefore, according to the Possessive Hypothesis, car in Sam's car would be more prominent than car in the/a car.

As stated previously, the Animacy Hypothesis and the Possessive Hypothesis are not mutually exclusive, and were they both to hold, the result would be that possessed animates are more prominent than either possessed inanimates or non-possessed animates; however, there might be another reason - irrespective of the combination of the previous two hypotheses - to expect increased prominence for possessed animates: their explicit denotation of interpersonal relationships (e.g. Sam's mother). As discussed in Section 1.2, it seems reasonable to assume, based on prior work, that humans' mental representations of interpersonal relationships are cognitively privileged (e.g. Cacioppo \& Hawkley, 2009; Eisenberger \& Cole, 2012). Based on findings within the social psychology, health, and memory literatures, we might additionally suspect that their linguistic realizations are privileged on the discourse level.

Therefore, our third hypothesis is the Interaction Hypothesis, whereby possessed animates are especially prominent in discourse - in excess of any additive effects of animacy and possession-due to the domain-general cognitive significance of interpersonal relationships. Accordingly, we would expect doctor in Sam's doctor to be especially prominent, in excess of any additive effects of animacy and possession status.

2. Testing our hypotheses with a sentence continuation experiment. Our examination of existing work has illustrated that there is still a significant gap in theories of discourse representation and processing concerning the nature of possessives. We therefore seek to investigate how possession affects a referent and whether different semantic possession relations modulate that effect. To this end, we have proposed three novel hypotheses concerning the representation of possessed referents, which we hope to support or reject using a sentence continuation experiment. The sentence continuation task is commonly viewed as providing a measure of referents' prominence. It builds on the common assumption that a referent's prominence is positively correlated with its likelihood of subsequent mention in the discourse (e.g. Givón, 1983; Arnold, 2001; Kehler et al., 2008; Kaiser, 2009; Kehler \& Rohde, 2013). Furthermore, existing discourse theory posits that the most prominent referents tend to appear as grammatical subjects (e.g. Chafe, 1976; Gordon et al., 1993; Stevenson et al., 1994). Thus we can measure which referents are most prominent by analyzing how often they are selected as continuation subjects (e.g. Givón, 1983; Ariel, 1988; Stevenson et al., 1994; Arnold, 2001). We also analyze mentions of entities throughout the continuation sentence as a further measure of discourse prominence, as well as looking at the linguistic form of mentions as a measure of entities' conceptual accessibility (e.g. Kaiser, 2009).

2.1. PARTICIPANTS. Data from 40 native English speakers is presented for analysis. All participants were 18 years of age or older and were recruited from Amazon Mechanical Turk. All of the participants included in the analysis reported being born in the United States and identified as native speakers of English. All reported normal or corrected-to-normal vision and normal hearing.

Jesse Storbeck and Elsi Kaiser:

Discourse behavior of possessives reflects the importance of interpersonal relationships. 
2.2. Design AND MATERIALS. The experiment had 56 items: 24 targets and 32 fillers. All target items followed the frame: [name] [nonce verb in simple past tense] [ $a$ vs. his/her] [animate vs. inanimate] (e.g. Jessica rulked an electrician; see example in Table 1).

\begin{tabular}{llll} 
Indefinite & Possessed & Indefinite & Possessed \\
Animate & Animate & Inanimate & Inanimate \\
\hline Jessica rulked & Jessica rulked & Jessica rulked & Jessica rulked \\
an electrician. & her electrician. & a chandelier. & her chandelier. \\
\hline
\end{tabular}

Table 1: An example target item (1 of 24) in each of the four conditions

We manipulated (i) possession: whether the object was possessed or indefinite and (ii) animacy: whether the direct object (which was the possession in the possessed conditions) was animate (and human) or inanimate.

Animate objects were all human role nouns (e.g. chauffeur, florist, housekeeper, stockbroker); inanimate objects were all concrete alienable possessions (e.g. jacket, stereo, toaster, umbrella). To minimize the potential for referential ambiguity in participants' continuations, the names (i.e. the prompt subjects) were all unambiguous with respect to their typically associated gender and matched for each item with human role noun objects which were stereotypically biased toward the opposite gender. The order of the genders in target items with animate objects was counterbalanced, as was the gender of the subjects overall. For each target item, animate objects were paired with inanimates that matched as closely as possible in lexical frequency, syllable length, and character length.

We chose to contrast possessive noun phrases with indefinites, rather than definites, because we found indefinites to sound more natural in the abbreviated contexts of our items; however, we intend to test definites as well in future work, since the givenness contexts which license definites are perhaps a more apt fit for possessives (e.g. Gundel et al., 1993; Barker, 2000).

Nonce verbs (e.g. blorned, chabbed, dasped, tammed) were used because they allowed the verb to remain constant within items, since predicates which naturally take animate objects are often unnatural with inanimate objects (and vice versa). The nonce verbs also limited the effects of verbal semantics on the continuations, perhaps from implicit causality (e.g. Hartshorne \& Snedeker, 2013) or distributional biases toward animate or inanimate objects.

The $2 \times 2$ (indefinite/possessive $\times$ animate/inanimate) design resulted in four conditions. Conditions were distributed across four experimental lists in a Latin square (i.e. within-subject and within-item design). Thus, each participant saw six items per condition. Targets and fillers on lists were interleaved in a pseudorandomized fashion. Four additional lists were created by reversing the trial order of the original lists, for a total of eight experimental lists.

2.3. Procedure. Before beginning the study, participants were told that they would read prompt sentences and write one-sentence continuations. Participants were instructed to make their continuations natural-sounding, not to copy-paste material from previous continuations or the prompts, and to limit their responses to a single complete sentence for each item. They completed three practice items (crucially without any possessive structures) and saw samples of acceptable continuations and unacceptable fragments. Other than the instructions against fragments and copy-paste, participants were assured multiple times that there were no right or wrong answers. Experimental items were presented on separate pages (see the example in Figure 1). 


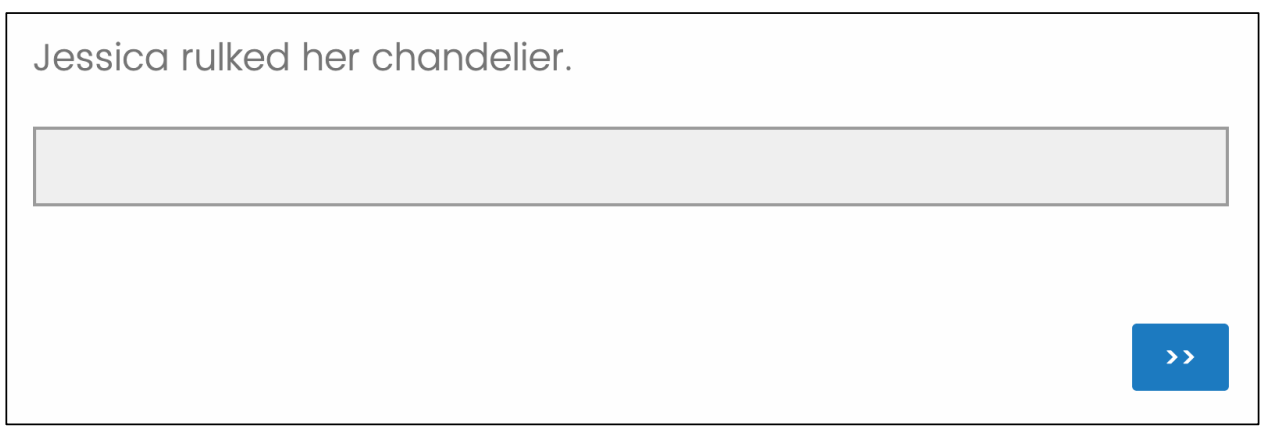

Figure 1: An example target item as it appeared to participants

2.4. ANNOTATION OF THE CONTINUATION DATA. In order to analyze participants' continuations, they were annotated by hand with respect to mentions of the preceding subject and object. Additionally, we annotated the head noun of the subject noun phrase for every clause in the continuation. Analyses below based on subject position are limited to the first independentclause subject in each continuation. Accordingly, if the prompt was Jennifer pranned her surgeon, and the participant wrote She asked him how long her surgery would last, the continuation would be coded as mentioning both the preceding subject and preceding object and mentioning the preceding subject as subject of the continuation. In the analyses below, a word was only counted as a mention of an entity if the head of the noun phrase referred to that entity; for example, for the prompt Daniel zatted his jacket, an instance of his jacket in the continuation would only count as a mention of the preceding object (jacket) and not the preceding subject (Daniel).

2.5. Predictions. Crucially, our three hypotheses introduced in Section 1.3 make different predictions of the results. Here we frame our predictions for the Animacy Hypothesis, Possessive Hypothesis, and Interaction Hypothesis in relation to mentions of the preceding object, since this is the locus of the experimental manipulation. Notably, these predictions are broadly relevant for both the subject-position and entire-continuation analyses. We consider subject position to reflect a "winner take all" measure of discourse prominence, under the widely held assumption that the most prominent referents in an utterance tend to be realized as grammatical subjects. On the other hand, we expect that mentions across the entire continuation will be a correlated but more inclusive measure that may pick up on finer differences in prominence.

As discussed in Section 1.3, the Animacy Hypothesis posits that, due to animates' general advantage in prominence over inanimates, animate possessions are therefore more prominent than inanimate ones. Accordingly, the Animacy Hypothesis predicts that animate possessions (e.g. his nurse) will be more likely to be mentioned in continuations than inanimate possessions (e.g. his jacket), and that this difference will be comparable in magnitude to the difference we observe for the indefinites (e.g. a nurse vs. a jacket). In statistical terms, we therefore expect a main effect of animacy with respect to mentions of the preceding object (without making any commitments as to the effect of possession).

The Possessive Hypothesis states that possessed referents are more prominent than simple noun phrases due to their referential and semantic complexity. Accordingly, it predicts that the possessed preceding objects will be more likely to be mentioned than the indefinites. We would expect such an effect of possession to apply approximately equally to animates and inanimates (i.e. a main effect of possession in our statistical models).

Finally, the Interaction Hypothesis theorizes that animate possessions are exceptionally prominent in discourse due to their denotation of interpersonal relationships. Therefore, we 
would expect possessed animates to receive an extra boost in likelihood of mention in participants' continuations (i.e. a statistical interaction of animacy and possession). Notably, animacy and possession could still contribute independently to the prominence of possessed animates following the logic of the Animacy Hypothesis and Possessive Hypothesis; however, the Interaction Hypothesis rests on observing a superadditive effect of animacy and possession together.

3. Results. All statistical analyses used generalized linear mixed-effects models implemented with the R package lme4 (Bates et al., 2015). All the models were fit to the binomial outcome of mentioning some entity in a certain position (1) or not (0). The independent variables animacy and possession were deviation coded (animate $=0.5$, inanimate $=-0.5$; possessive $=0.5$, indefinite $=-0.5$ ). We used the maximal random effects structure in each model that did not result in nonconvergence (Barr et al., 2013). When a model's random effects structure needed to be reduced due to nonconvergence, we prioritized the inclusion of random slopes for participants.

3.1. Mentions In SUBJECT POSITION. We first analyzed the subject position of continuations to see whether participants mentioned the preceding subject, object, or a third party not mentioned in the prompt. When a continuation contained multiple clauses, we analyzed the subject of the first independent clause. A visualization of these data is given below in Figure 2.

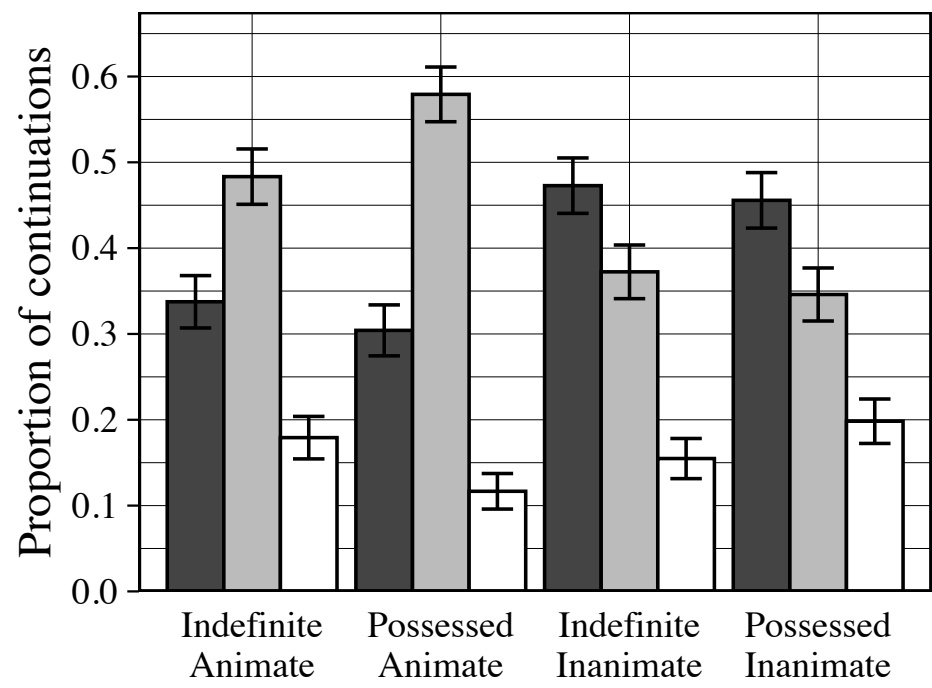

Continuation subject refers to preceding...

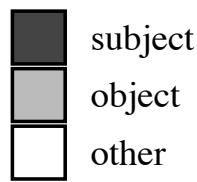

Figure 2: Does the subject of the continuation sentence refer back to the preceding subject, preceding object, or something else? (proportions are separated by condition)

We fit two models which predicted the probability of the continuation subject referring (with any linguistic form) to the preceding subject (Model 1) or preceding object (Model 2). Model 1 revealed an animacy effect, whereby the presence of an animate object in the prompt sentence significantly reduced the likelihood of the continuation subject referring to the prompt subject (i.e. the proper name) $(\mathrm{p}<0.01)$. This main effect of animacy seems to reflect increased competition for prominence between the preceding subject and object when the object is animate. Neither the main effect of possession nor its interaction with animacy were significant $(\mathrm{p}=0.35$ and $\mathrm{p}=0.74$, respectively).

Like the model for the preceding subject, Model 2 (predicting the probability of mentioning the preceding object in subject position) also showed a significant main effect of animacy ( $\mathrm{p}<$ 0.001). This finding illustrates that animate objects had a significantly greater chance of being 
mentioned in subject position compared to inanimate objects, reflecting the well-known advantage in prominence that animacy confers. There was no significant main effect of possession $(p=0.30)$, but the model did show a significant interaction of possession and animacy $(p=0.04)$, which reflects a boost in the likelihood of mention for animate possessions. To further examine this interaction, we fit an additional model to test for a simple effect of possession within the animate conditions; this analysis revealed a significant simple effect of possession $(p=0.02)$, supporting the interpretation that preceding animate objects were more likely to be mentioned as continuation subjects when they were possessed. There was no corresponding simple effect of possession in the inanimate conditions $(p=0.43)$. This finding suggests that animate possessions are especially prominent in discourse and consequently supports the Interaction Hypothesis.

3.2. Mentions IN ALL POSITIONS. We turn now to the analysis of mentions in all positions of the continuations. A visualization of references anywhere in the continuation (with any linguistic form) is presented as Figure 3. The statistical analysis proceeded in much the same way as the subject-position analysis, except the binomial outcome was mention of a particular entity across the entire continuation. Again, we fit two models, one for the preceding subject (Model 3) and one for the preceding object (Model 4).

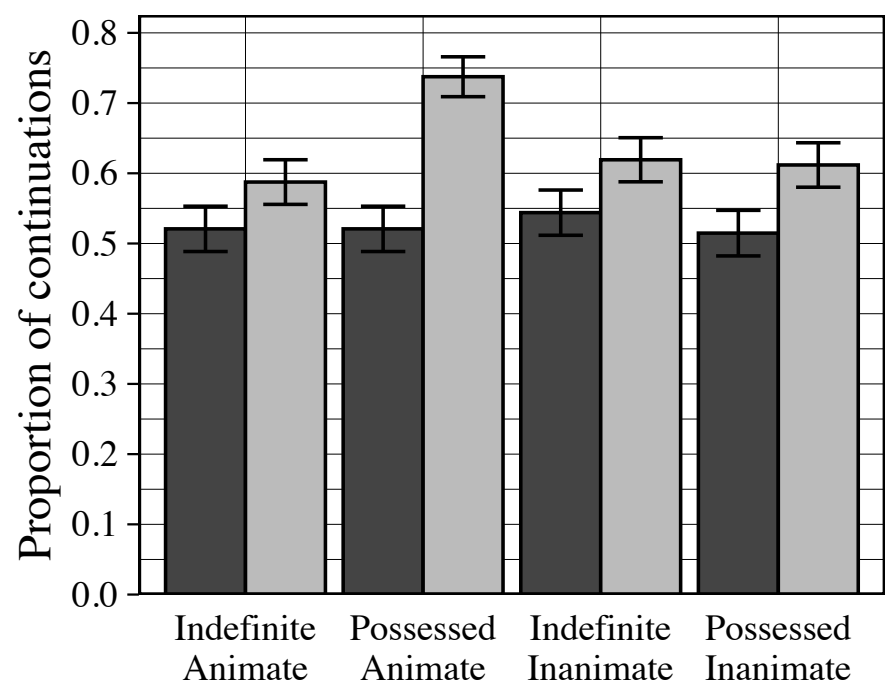

Continuation contains mention of preceding...

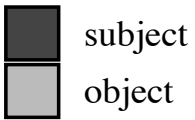

Figure 3: Does the continuation sentence contain a reference to the preceding subject or object? (proportions are separated by condition)

Model 3 (predicting the likelihood of mentioning the preceding subject anywhere in the continuation) revealed no significant effects (all $\mathrm{p}>0.50$ ). This result contrasts with the corresponding subject-position analysis (Model 1, Section 3.1), which showed an animacy effect for mentions of the preceding subject. While the preceding subject was less likely in animate conditions to be mentioned as the subject of the continuation (as shown in Figure 2), by the end of the continuation, all the conditions showed a similar likelihood of having mentioned the preceding subject somewhere (as shown in Figure 3).

Model 4 (predicting the likelihood of mentioning the preceding object anywhere in the continuation) showed a significant effect of possession $(\mathrm{p}<0.01)$ and, like the corresponding subject-position analysis (Model 2, Section 3.1), a significant interaction of possession and animacy $(\mathrm{p}<0.01)$. This interaction shows that possessed animates were especially likely to be 
mentioned across the entire continuation. Finally, we again sought to confirm this interaction by testing for a simple effect of possession within just the animate conditions; like the corresponding subject-position analysis in Section 3.1, this follow-up model showed that possessed animates were significantly more likely than their indefinite counterparts to be mentioned in continuations $(\mathrm{p}<0.001)$; however, no such simple effect was present for the inanimate conditions $(\mathrm{p}=0.83)$. Therefore, our results again support the Interaction Hypothesis and the theory that animate possessions enjoy special discourse prominence.

4. Discussion. Not all referents are equally prominent in comprehenders' mental representations of discourse. We report an experiment investigating the discourse behavior of nominal possessives (e.g. Sam's car), which differ from simpler definite or indefinite nouns (e.g. althe car) by referencing two entities: a possessor (Sam) and a possession (car). Drawing on research in linguistics and other cognitive domains, we propose in Section 1.3 three hypotheses about the prominence of animate and inanimate possessions: the Animacy Hypothesis, Possessive Hypothesis, and Interaction Hypothesis. We tested these hypotheses using a sentence continuation task, where we analyzed how likely participants were to mention referents from a prompt sentence depending on the referents' possession status (possessed vs. indefinite) and animacy (human role nouns vs. alienable concrete objects).

Given that we observed significant interactions of animacy and possession in both the subject-position and entire-continuation analyses, our results support the Interaction Hypothesis. Because participants were more likely to mention possessed animates (both as subjects and in general) in excess of the combined independent effects of animacy and possession, we conclude that possessed animates get an exceptional boost in discourse prominence-beyond what is predicted simply based on the independent effects of animacy and possession.

We suggest that possessed animates' special status in discourse may relate to the fact that they explicitly denote interpersonal relationships. Prior work in the diverse research domains of health, social cognition, and memory has shown that an individual's relationships relative to other humans are of critical importance. We suggest that the exceptional discourse behavior of possessed animates observed in the current study is linked to a more general cognitive privilege for interpersonal relationships.

Regarding prior work on the discourse behavior of possessives, our results also address a debate within the Centering Theory literature mentioned in Section 1.1. Researchers in this field have proposed two competing accounts for the relative prominence of possessors and possessions in English $s$-genitives. The first is that possessors are always more prominent than possessions (Chae, 2003). Alternatively, Di Eugenio (1998) has proposed that the prominence ranking depends on the animacy of the possession. According to this account, possessors are more prominent than inanimate possessions, but animate possessions are more prominent than their possessors. The results of our experiment show that animate and inanimate possessions behave quite differently on the discourse level, with animate possessions receiving more prominence than their animacy alone would predict. Therefore, our results are more compatible with Di Eugenio's account, which differentiates the discourse behavior of animate and inanimate possessions and confers extra prominence on possessed animates.

Finally, some readers may wonder why we did not find a clear overall effect of possessionwhy are possessed nouns not mentioned more (or perhaps less) often than indefinites? It seems reasonable to assume that possession must have some baseline effect on the discourse representation of a referent, irrespective of animacy; however, the reason our results do not show this effect 
may be attributable to our comparison of possessives to indefinites. We anticipate that choosing a different class of nominals to compare with possessives (e.g. definites) might result in a detectable baseline possessive effect. Crucially, however, we do not expect that discourse-related differences between definites, indefinites, and possessives (e.g. givenness, specificity) would systematically vary across our animate and inanimate conditions. Therefore, these factors cannot explain the animacy-by-possession interactions we observe in the current experiment. Furthermore, in future work comparing possessives to definites, we would still predict that animacy would interact with possession, yielding a result that supports the Interaction Hypothesis.

\section{References}

Ariel, Mira. 1988. Referring and accessibility. Journal of Linguistics 24. 65-87. https://doi.org/10.1017/S0022226700011567

Arnold, Jennifer E. 2001. The Effect of Thematic Roles on Pronoun Use and Frequency of Reference Continuation. Discourse Processes $31 . \quad$ 137-162. https://doi.org/10.1207/S15326950DP3102_02

Arnold, Jennifer and Griffin, Zenzi M. 2007. The effect of additional characters on choice of referring expression: Everyone counts. Journal of Memory and Language 56. 521-536. https://doi.org/10.1016/j.jml.2006.09.007

Barker, Chris. 2000. Definite Possessives and Discourse Novelty. Theoretical Linguistics 26. 211-227. https://doi.org/10.1515/thli.2000.26.3.211

Barr, Dale J., Levy, Roger, Scheepers, Christoph and Tily, Harry J. 2013. Random effects structure for confirmatory hypothesis testing: Keep it maximal. Journal of Memory and Language 68. 255-278. https://doi.org/10.1016/j.jml.2012.11.001

Bates, Douglas, Mächler, Martin, Bolker, Ben and Walker, Steve. 2015. Fitting Linear MixedEffects Models Using lme4. Journal of Statistical Software 67. 1-48. https://doi.org/10.18637/jss.v067.i01

Bock, Kathryn, Loebell, Helga and Morey, Randal. 1992. From conceptual roles to structural relations: Bridging the syntactic cleft. Psychological Review 99. 150-171. https://doi.org/10.1037//0033-295X.99.1.150

Bonin, Patrick, Gelin, Margaux and Bugaiska, Aurélia. 2014. Animates are better remembered than inanimates: further evidence from word and picture stimuli. Memory \& Cognition 42. 370-382. https://doi.org/10.3758/s13421-013-0368-8

Branigan, Holly P., Pickering, Martin J. and Tanaka, Mikihiro. 2008. Contributions of animacy to grammatical function assignment and word order during production. Lingua 118. 172189. https://doi.org/10.1016/j.lingua.2007.02.003

van den Broek, Paul, Risden, Kirsten, Fletcher, Charles R. and Thurlow, Richard. 1996. A "Landscape" View of Reading: Fluctuating Patterns of Activation and the Construction of a Stable Memory Representation. In B. K. Britton \& A. C. Graesser (eds.), Models of Understanding Text, 165-187. Lawrence Erlbaum Associates, Inc.

Cacioppo, John T. and Hawkley, Louise C. 2009. Perceived social isolation and cognition. Trends in Cognitive Sciences 13. 447-454. https://doi.org/10.1016/j.tics.2009.06.005

Cacioppo, John T., Hughes, Mary Elizabeth, Waite, Linda J., Hawkley, Louise C. and Thisted, Ronald A. 2006. Loneliness as a Specific Risk Factor for Depressive Symptoms. Psychology and Aging 21. 140-151. https://doi.org/10.1037/0882-7974.21.1.140

Jesse Storbeck and Elsi Kaiser:

Discourse behavior of possessives reflects the importance of interpersonal relationships. 
Chae, Sook-Hee. 2003. Possessives in Naturally Occurring Discourse: A Centering Approach. University of Pennsylvania Working Papers in Linguistics 9. https://repository.upenn.edu/pwpl/vol9/iss1/6

Chafe, Wallace L. 1976. Givenness, Contrastiveness, Definiteness, Subjects, Topics, and Point of View. In Charles N. Li (ed.), Subject and Topic, 25-55. New York: Academic Press.

Crawley, Rosalind A., Stevenson, Rosemary J. and Kleinman, David. 1990. The use of heuristic strategies in the interpretation of pronouns. Journal of Psycholinguistic Research 19. $245-$ 264. https://doi.org/10.1007/bf01077259

Dahl, Östen. 2008. Animacy and egophoricity: Grammar, ontology and phylogeny. Lingua 118. 141-150. https://doi.org/10.1016/j.lingua.2007.02.008

Dahl, Östen and Fraurud, Kari. 1996. Animacy in Grammar and Discourse. In Thorstein Fretheim and Jeanette K. Gundel (eds.), Reference and Referent Accessibility, 47-64. Amsterdam: Benjamins. https://doi.org/10.1075/pbns.38.04dah

Di Eugenio, Barbara. 1998. Centering in Italian. In Marilyn Walker, Aravind Joshi and Ellen Prince (eds.), Centering Theory in Discourse, 115-137. https://arxiv.org/abs/cmp$\lg / 9608007$

Eisenberger, Naomi I. and Cole, Steve W. 2012. Social neuroscience and health: neurophysiological mechanisms linking social ties with physical health. Nature Neuroscience 15. 669674. https://doi.org/10.1038/nn.3086

Fisher, Ronald P. and Craik, Fergus I. M. 1980. The effects of elaboration on recognition memory. Memory \& Cognition 8. 400-404. https://doi.org/10.3758/BF03211136

Fukumura, Kumiko and van Gompel, Roger P. G. 2011. The effect of animacy on the choice of referring expression. Language and Cognitive Processes 26. 1472-1504. https://doi.org/10.1080/01690965.2010.506444

Givón, T. 1983. Topic Continuity in Discourse: A quantitative cross-language study. John Benjamins Publishing Company: Philadelphia. https://doi.org/10.1075/tsl.3

Gordon, Peter C., Grosz, Barbara J. and Gilliom, Laura A. 1993. Pronouns, names, and the centering of attention in discourse. Cognitive Science $17 . \quad 311-347$. https://doi.org/10.1207/s15516709cog1703_1

Grosz, Barbara J., Joshi, Aravind K. and Weinstein, Scott. 1995. Centering: a framework for modeling the local coherence of discourse. Computational Linguistics 21. 203-225. https://www.aclweb.org/anthology/J95-2003

Gundel, Jeanette K., Hedberg, Nancy and Zacharski, Ron. 1993. Cognitive Status and the Form of Referring Expressions in Discourse. Language $69 . \quad 274-307$. https://doi.org/10.2307/416535

Hartshorne, Joshua K. and Snedeker, Jesse. 2013. Verb argument structure predicts implicit causality: The advantages of finer-grained semantics. Language and Cognitive Processes 28. 1474-1508. https://doi.org/10.1080/01690965.2012.689305

Haspelmath, Martin. 2017. Explaining alienability contrasts in adpossessive constructions: Predictability vs. iconicity. Zeitschrift für Sprachwissenschaft $36 . \quad 193-231$. https://doi.org/10.1515/zfs-2017-0009

Hofmeister, Philip. 2011. Representational complexity and memory retrieval in language comprehension. Language and Cognitive Processes $26 . \quad 376-405$. https://doi.org/10.1080/01690965.2010.492642 
Holt-Lunstad, Julianne, Smith, Timothy B. and Layton, J. Bradley. 2010. Social Relationships and Mortality Risk: A Meta-analytic Review. PLoS Medicine 7. e1000316. https://doi.org/10.1371/journal.pmed.1000316

Kaiser, Elsi. 2009. Investigating effects of structural and information-structural factors on pronoun resolution. In Malte Zimmermann and Caroline Féry (eds.), Information Structure: Theoretical, Typological, and Experimental Perspectives, 332-353. Oxford: Oxford University Press. https://doi.org/10.1093/acprof:oso/9780199570959.003.0014

Karimi, Hossein and Ferreira, Fernanda. 2016. Informativity renders a referent more accessible: Evidence from eyetracking. Psychonomic Bulletin \& Review 23. 507-525. https://doi.org/10.3758/s13423-015-0917-1

Kehler, Andrew, Kertz, Laura, Rohde, Hannah and Elman, Jeffrey L. 2008. Coherence and Coreference Revisited. Journal of Semantics 25. 1-44. https://doi.org/10.1093/jos/ffm018

Kehler, Andrew and Rohde, Hannah. 2013. A probabilistic reconciliation of coherence-driven and centering-driven theories of pronoun interpretation. Theoretical Linguistics 39. 1-37. https://doi.org/10.1515/tl-2013-0001

Miller, Gregory, Chen, Edith and Cole, Steve W. 2009. Health Psychology: Developing Biologically Plausible Models Linking the Social World and Physical Health. Annual Review of Psychology 60. 501-524. https://doi.org/10.1146/annurev.psych.60.110707.163551

Nairne, James S. 2010. Adaptive Memory: Evolutionary Constraints on Remembering. In Brian H. Ross (ed.), Psychology of Learning and Motivation, 1-32: Academic Press. https://doi.org/10.1016/S0079-7421(10)53001-9

Nairne, James S., VanArsdall, Joshua E., Pandeirada, Josefa N. S., Cogdill, Mindi and LeBreton, James M. 2013. Adaptive Memory: The Mnemonic Value of Animacy. Psychological Science 24. 2099-2105. https://doi.org/10.1177/0956797613480803

Prat-Sala, Mercè and Branigan, Holly P. 2000. Discourse Constraints on Syntactic Processing in Language Production: A Cross-Linguistic Study in English and Spanish. Journal of Memory and Language 42. 168-182. https://doi.org/10.1006/jmla.1999.2668

Rosenbach, Anette. 2002. Genitive Variation in English. De Gruyter: Berlin/Boston. https://doi.org/10.1515/9783110899818

Stevenson, Rosemary J., Crawley, Rosalind A. and Kleinman, David. 1994. Thematic roles, focus and the representation of events. Language and Cognitive Processes 9. 519-548. https://doi.org/10.1080/01690969408402130

Tilvis, R. S., Kahonen-Vare, M. H., Jolkkonen, J., Valvanne, J., Pitkala, K. H. and Strandberg, T. E. 2004. Predictors of Cognitive Decline and Mortality of Aged People Over a 10-Year Period. The Journals of Gerontology: Series A 59. M268-274. https://doi.org/10.1093/gerona/59.3.m268

Troyer, Melissa, Hofmeister, Philip and Kutas, Marta. 2016. Elaboration over a Discourse Facilitates Retrieval in Sentence Processing. Frontiers in Psychology 7. 374. https://doi.org/10.3389/fpsyg.2016.00374

VanArsdall, Joshua E., Nairne, James S., Pandeirada, Josefa N. S. and Blunt, Janell R. 2012. Adaptive Memory: Animacy Processing Produces Mnemonic Advantages. Experimental Psychology 60. 172-178. https://doi.org/10.1027/1618-3169/a000186

Walker, Marilyn A. and Prince, Ellen F. 1996. A Bilateral Approach to Givenness: A HearerStatus Algorithm and a Centering Algorithm. In Thorstein Fretheim and Jeanette K. Gundel (eds.), Reference and Referent Accessibility, 291-312. Amsterdam: Benjamins. https://doi.org/10.1075/pbns.38.17wal

Jesse Storbeck and Elsi Kaiser:

Discourse behavior of possessives reflects the importance of interpersonal relationships. 